\title{
Definite Residual Metabolic Tumor Activity
}

National Cancer Institute

\section{Source}

National Cancer Institute. Definite Residual Metabolic Tumor Activity. NCI Thesaurus.

Code C123411.

A finding of strong focal metabolic activity at the primary or nodal sites that is greater than liver uptake. 